\title{
Impact of Hospital Rehabilitation on Functional Outcomes and Quality of Life after Total Knee Arthroplasty
}

\author{
Ahmet Özgür YILDIRIM¹', Öznur ÖKEN², Özdamar Fuad ÖKEN¹, Belma Füsun KÖSEOĞLU², Nebahat SEZER², Ahmet UÇANER \\ ${ }^{1}$ Clinic of Orthopaedia and Traumatology, Ankara Numune Training and Research Hospital, Ankara, Turkey \\ ${ }^{2}$ Clinic of Physical Medicine and Rehabilitation, Ankara Physical Medicine and Rehabilitation Training and Research Hospital, Ankara, Turkey \\ ${ }^{3}$ Department of Physical Medicine and Rehabilitation, Ankara Yıldırım Beyazıt University, Ankara, Turkey
}

\begin{abstract}
Objective: The objective of the study was to investigate the impact of rehabilitation program performed in hospital on functional outcomes and quality of life after total knee arthroplasty (TKA).

Material and Methods: The trial included 374 patients (307 female and 67 male; age range 47-85 years) who had undergone TKA. The patients in group I $(n=123)$ were included in an inpatient rehabilitation program at a physical medicine and rehabilitation hospital, whereas the patients in group II ( $n=251)$ were provided a home exercise program. Knee pain at rest using the visual analog scale, functional and knee scores of the Knee Society Clinical Rating System, and Short Form-36 (SF-36) questionnaire were used as outcome measures.

Results: The percentage change in the physical component score of the SF-36 was significantly higher in the patients of the hospital-based program than in those of the home-based program, whereas the mental component score revealed no difference between the groups ( $p=0.001$ and $p>0.05$, respectively). The percentage of improvement was not different between groups in terms of knee pain and knee score of the Knee Society $(p>0.05)$.

Conclusion: The results demonstrated that the rehabilitation program performed in the hospital was more effective with respect to the functional status than the home exercise program after TKA.

Keywords: Total knee arthroplasty, home-based rehabilitation, inpatient rehabilitation
\end{abstract}

\section{Introduction}

Currently, total knee arthroplastic surgery is an important treatment choice in the management of the patients with moderate to severe knee osteoarthritis $(\mathrm{OA})(1)$. The main objectives of total knee arthroplasty (TKA) are to reduce pain, achieve a maximum level of functional independence, and consequently to increase the quality of life (2). Successful functional outcomes are because of appropriate and timely surgical treatment as well as the type of postoperative rehabilitation (3).

It is predicted that over $85 \%$ of the patients with TKA will not require an extended rehabilitation protocol to recover knee function (4). The main goals of rehabilitation procedures are to prevent complications and enable early return to activities of daily living by saving the replaced joint (5). However, on discharge from the orthopedic clinic after TKA, it is often difficult to

Address for Correspondence: Öznur Öken, MD, Ankara Fizik Tedavi ve Rehabilitasyon Eğitim ve Araştırma Hastanesi, Fiziksel Tıp ve Rehabilitasyon Kliniği, Ankara, Türkiye. Phone: +903123432388 E-mail: okenoznur@yahoo.com 
decide whether a patient will require inpatient or home-based rehabilitation. Often, criteria, such as age, gender, medical status, co-morbidities and patient preference, are used to decide the kind of postoperative rehabilitation (6). The validated Risk Assessment and Prediction Tool (RAPT) $(6,7)$ effectively identifies the patients in most need of extended rehabilitation and facilitates this decision on discharge.

The purpose of the present study was to determine the following:

- Whether functional outcome differs between hospital rehabilitation and home exercise programs.

- Whether hospital rehabilitation programs have a positive impact in terms of the quality of life in the patients who have undergone total knee arthroplastic surgery.

\section{Material and Methods}

\section{Participants}

The study included 374 patients [307 females, 67 males; mean age $\pm S D$ of $66.8 \pm 8.3$ (range $47-85$ ) years] who had undergone an elective primary TKA because of primary OA of the knee. These patients were operated between 2008 and 2011 in the Orthopaedics and Traumatology Clinic of Ankara Numune Training and Research Hospital.

A retrospective analysis was performed of the prospectively collected data. Cemented total joint replacement (Biomet, Merck, Bridgend, UK) was performed using the medial parapatellar retinacular approach.

The patients with bilateral arthroplasty, revision arthroplasty, previous problems of the operated and/or non-operated leg (such as previous fractures, arthritis, metastatic, or primary tumor of the knee), any complication due to operation (such as deep venous thrombosis, nerve lesions, infections, or complex regional pain syndrome), and patients with cognitive impairment were excluded.

The study protocol was approved by the local Hospital Medical Ethics Committee, and written informed consent was provided by all participants.

\section{Study Design}

All patients were allowed full weight bearing the second day after surgery using crutches, instructed isometric exercises, and continued passive motion. The patients were discharged from hospital after approximately the first week post-surgery with $0-90^{\circ}$ of range of motion.

On the basis of RAPT, the study patients with a score $\leq 6$ $(n=123)$ were admitted to an inpatient rehabilitation program at the physical medicine and rehabilitation (PM\&R) hospital (Group I). In addition to the total knee arthroplasty protocol developed by Becker (8), these patients underwent a rehabilitation program, including strengthening and range of motion exercises, cold pack, transcutaneous electrical nerve stimulation (TENS), and therapeutic electric stimulation of the quadriceps muscle, for 6 weeks.
In contrast, the patients with a RAPT score $\geq 6 \quad(n=251)$ were assigned to a home-based exercise program (Group II). These patients performed the home exercises program, including strengthening and range of motion exercises, three times a day for 6 weeks. Follow-up assessment was conducted in the $6^{\text {th }}$ week after surgery for both groups.

\section{Outcome Measures}

In both groups, pain intensity during rest was measured on a $100-\mathrm{mm}$ visual analogue scale (VAS) (9). The endpoints of the scale were anchored at $0 \mathrm{~mm}$ with the words "no pain" and at $100 \mathrm{~mm}$ with "unbearable pain."

Knee pain together with motion, stability, and functional capacity of the patients were measured with the Knee Society Clinical Rating System (KSS) (10). KSS comprises two scores: the knee score reflects VAS score of pain, range of motion, and stability of the knee and the functional score reflects the functional capacity of the patients during walking and stair climbing. After TKA, both these scores were recorded before and after rehabilitation by the same surgeon.

The Medical Outcomes Study Short Form-36 (the SF-36) questionnaire (the Turkish version) (11) was used to measure the quality of life. SF-36 includes one multi-item scale that assesses eight health concepts divided into two main groups: the physical components summary (PCS) and mental components summary (MCS) scores. SF-36 scales are standardized to range from 0 to 100 with a higher score indicating better health status. The validity and reliability of the Turkish version of the SF-36 is well validated.

\section{Statistical Analysis}

For continuous variables, the groups were compared using the t-test for independent samples and the Mann-Whitney U-test for categorical data. The percentage change between pre- and post-treatment data for both groups was calculated as 100x (post-treatment-pretreatment/pretreatment). The group means and percentage changes were compared between Group

Table 1. Characteristics of the patients in the two study groups

\begin{tabular}{lccc} 
& $\begin{array}{c}\text { Group I: } \\
\text { Hospital based } \\
(\mathbf{n = 1 2 3})\end{array}$ & $\begin{array}{c}\text { Group II: } \\
\text { Home based } \\
(\mathbf{n}=\mathbf{2 5 1})\end{array}$ & $\mathbf{p}$ value \\
\hline Age (years) (min-max) & $\begin{array}{c}65.8 \pm 8.3 \\
(50-84)\end{array}$ & $\begin{array}{c}67.1 \pm 7.4 \\
(35-96)\end{array}$ & 0.251 \\
& $98 / 25$ & $209 / 42$ & 0.395 \\
Gender (female/male) (\%) & $(79.7 / 20.3)$ & $(83.3 / 16.7)$ & \\
& $66 / 57$ & $121 / 130$ & 0.286 \\
$\begin{array}{l}\text { Operated side } \\
\text { (right/left) (\%) }\end{array}$ & $(53.7 / 46.3)$ & $(44.2 / 55.8)$ & \\
$\begin{array}{l}\text { Body mass index } \\
\text { (min-max) }\end{array}$ & $34.2 \pm 4.4$ & $34.6 \pm 4.9$ & 0.335 \\
$\begin{array}{l}\text { Duration of hospital- } \\
\text { based rehabilitation }\end{array}$ & $24-44.6)$ & $(23.4-44.5)$ & \\
(days) (min-max) & $(15-36)$ & & \\
\hline Values are mean \pm SD & & & \\
\end{tabular}


Table 2. Comparison of the measured values in the two study groups before and after rehabilitation

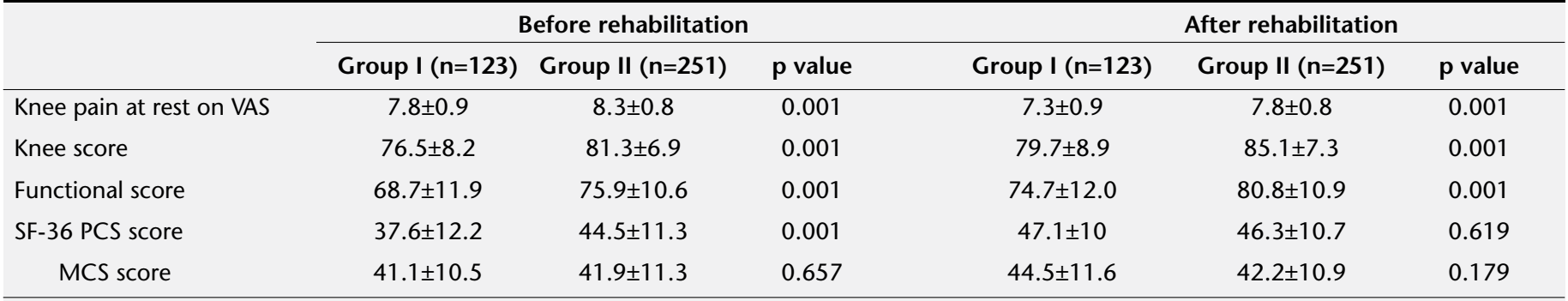

SF-36: Short-Form-36; PCS: physical components summary; MCS: mental components summary; VAS: visual analog score

Values are mean $\pm \mathrm{SD}$

Table 3. Comparison of the two groups in terms of improvement percentage between before and after rehabilitation

\begin{tabular}{lccc} 
& $\begin{array}{c}\text { Group I } \\
(\mathbf{n}=\mathbf{1 2 3})\end{array}$ & $\begin{array}{c}\text { Group II } \\
(\mathbf{n}=\mathbf{2 5 1})\end{array}$ & $\mathbf{p}$ value \\
\hline$\Delta$ Knee pain at rest by VAS (\%) & $56.7 \pm 8$ & $65.4 \pm 9.1$ & 0.369 \\
$\Delta$ Knee score (\%) & $43.2 \pm 4.8$ & $38 \pm 5.1$ & 0.338 \\
$\Delta$ Functional score (\%) & $69.3 \pm 8.1$ & $53.3 \pm 6.8$ & 0.046 \\
$\Delta$ SF-36 PCS score (\%) & $40.2 \pm 5.7$ & $10.2 \pm 3.7$ & $<0.001$ \\
\multicolumn{1}{c}{ MCS score (\%) } & $14.6 \pm 4.5$ & $10.5 \pm 4.9$ & 0.578 \\
\hline
\end{tabular}

$\Delta$ : percentage of improvement between before and after rehabilitation;

SF-36: Short-Form-36; PCS: physical components summary; MCS: mental components summary; VAS: visual analog score

I and Group II using Mann-Whitney $U$ test and Wilcoxon signed ranks tests.

For comparing the changes within the groups before and after rehabilitation, a paired sample t-test was used. Data were analyzed using SPSS for Windows, Version 16.0. Chicago, SPSS Inc. The level of statistical significance was set at $p<0.05$.

\section{Results}

A total of 374 patients were enrolled in this study; there were no significant differences between the two groups with regard to age, gender, operated side, body mass index, and duration of rehabilitation (Table $1 ; p>0.05$ ). The length of rehabilitation in the hospital was (mean \pm SD) $24.1 \pm 5.8$ (min-max, 15-36) days (Table 1).

There was a significant difference between the two groups in knee pain at rest (VAS) both before and after rehabilitation (Table 2; $\mathrm{p}$ 0.05). In the home-based group, both the knee and functional scores of the patients was higher than those in the hospital-based group both before and after rehabilitation (Table 2; $\mathrm{p}<0.05)$.

Physical components summary CS score of SF-36 was significantly higher in Group II than in Group I ( $p=0.001)$; however, there was no difference in MCS score of SF-36 postoperatively (before rehabilitation) ( $p>0.05)$. Although both PCS and MCS scores revealed a significant improvement in Group I $(p=0.001$ and $p=0.019$, respectively) (paired t-test), no significant differ- ence was observed in Group II before and after rehabilitation (Table 2; p>0.05).

After rehabilitation, the differences between the two groups for PCS and MCS scores were no longer significant ( $p>0.05$ ).

There were no significant differences between the groups for knee pain at rest (VAS) and functional knee score ( $p>0.05)$.

The percentage change in PCS score of SF-36 was significantly higher in the patients of the hospital-based program than in those of the home-based program, whereas MCS score revealed no difference between the groups $(p=0.001$ and $p>0.05$, respectively) (Table 3 ).

\section{Discussion}

The present study compared the effects of a hospital rehabilitation program with a home exercise program with respect to functional improvement and the quality of life after TKA.

The hospital rehabilitation program resulted in a significant improvement in functional scores of the knee compared with the home-based program, whereas the pain and knee motion scores demonstrated no differences between the two groups.

It is generally accepted that home-based exercise programs are as effective as inpatient rehabilitation after TKA $(12,13)$. Mahomed et al. (14) found no significant differences between inpatient and home-based rehabilitation groups at a mean follow-up of 8 months in terms of the quality of life and patient satisfaction. However, our results concur with those of others suggesting the additional benefit of postoperative rehabilitation in a PM\&R ward after TKA in terms of increasing functional status. KSS score reflects functional capacity of the patients during walking and stair climbing. The difference in percentage improvement between the functional and knee scores may be explained by the fact that electrical stimulation was applied to the quadriceps muscle that plays an important role during walking and stair climbing. Furthermore, it is reported that quadriceps strength in the TKA knee rapidly increases with electrical stimulation compared with that in the other knee and compared with the patients who did not receive electrical stimulation (15).

Another possibility is that training in walking/stair climbing may not have been effectively performed by the patients at 
home and/or that training with a physiotherapist in the hospital may have increased the confidence of the patients.

Moreover, we observed that PCS score of the health-related quality of life (HRQOL) was significantly improved after the inpatient rehabilitation program. This result is consistent with another study demonstrating a positive change in HRQOL, particularly in the physical component, in favor of the intensive functional rehabilitation group at short- and mid-term follow-up (16). The authors recommend that more intensive rehabilitation should be promoted in the sub-acute recovery period after TKA to optimize functional outcomes in the first year.

After TKA, it is reported that factors, such as the demographic data, co-morbidities, surgeon's advice, and patient's preference, influence the decision as to whether the patients will be discharged or assigned to inpatient rehabilitation (17). RAPT $(18,19)$ identifies three levels of risk of the patients requiring extended inpatient rehabilitation after hip or knee arthroplastic surgery with an accuracy rate of $89 \%$ for those at increased risk. Because RAPT effectively identifies those most in need of inpatient rehabilitation and improves the efficacy of discharge decision-making (7), It is possible that the improvement of functional outcomes in the hospital rehabilitation group may be because of the use of RAPT for decision-making.

Limitations of the current study include the following:

- Long-term follow-up results were not taken

- $\quad$ The patients were not randomized

- The fact that we did not evaluate the satisfaction of the patients

The functional component of KSS has recently been updated and validated and now includes components, such as standard activities of daily living, patient-specific sports and recreational activities, patient satisfaction, and patient expectations $(20,21)$. For further studies, the new KSS scoring system will be available.

\section{Conclusion}

In the rehabilitation of TKA, supervised rehabilitation program performed in the hospital appears to be superior to home exercise programs in terms of functional outcomes and the quality of life.

Future studies that are randomized and controlled should examine the long-term effects of hospital-based vs. home-based exercise programs after TKA.

Ethics Committee Approval: Ethics committee approval was received for this study from the ethics committee of Ankara Numune Training and Research Hospital.

Informed Consent: Written informed consent was obtained from patients who participated in this study.

Peer-review: Externally peer-reviewed.

Author Contributions: Concept - Ö.Ö.; Design - Ö.Ö.; Supervision B.F.K., A.U.; Resource - A.Ö.Y.; Materials - A.Ö.Y., F.Ö., N.S., Ö.Ö.; Data Collection and/or Processing - A.Ö.Y., Ö.Ö., F.Ö.; Analysis and/or Inter- pretation - A.Ö.Y., Ö.Ö., F.Ö.; Literature Review - A.Ö.Y., Ö.Ö., F.Ö.; Writer - A.Ö.Y., Ö.Ö., F.Ö.; Critical Review - B.F.K.

Conflict of Interest: No conflict of interest was declared by the authors.

Financial Disclosure: The authors declared that this study has received no financial support.

\section{References}

1. Guyton JL. Arthroplasty of ankle and knee. In: Campbell's Operative Orthopaedics. 9th ed, St. Louis, Mosby-Year Book, 1998, p.232-95,

2. Dieppe P, Basler HD, Chard J, Croft P, Dixon J, Hurley M, et al. Knee replacement surgery for osteoarthritis: effectiveness, practice variations, indications and possible determinants of utilization. Rheumatology 1999;38:73-83. [CrossRef]

3. Shields RK, Enloe LJ, Leo KC. Health-related quality of life in patients with total hip or knee replacement. Arch Phys Med Rehabil 1999;80:572-9. [CrossRef]

4. Ranawat CS, Ranawat AS, Mehta A. Total knee arthroplasty rehabilitation protocol: what makes the difference? J Arthroplasty 2003;18:27-30. [CrossRef]

5. Demir H, Çalış M. Rehabilitation of knee arthroplasty. Erciyes Med J 2002;24:194-201.

6. Coudeyre E, Lefevre-Colau MM, Griffon A, Camilleri A, Ribinik $P_{1}$ Revel $M$, et al. Is there predictive criteria for transfer of patients to a rehabilitation ward after hip and knee total arthroplasty? Elaboration of French clinical practice guidelines. Ann Readapt Med Phys 2007;50:327-36. [CrossRef]

7. Oldmeadow LB, McBurney H, Robertson V], Kimmel L, Elliott B. Targeted postoperative care improves discharge outcome after hip or knee arthroplasty. Arch Phys Med Rehabil 2004;85:1424-7. [CrossRef]

8. Total Knee Arthroplasty Protocol. Developed with Michael Becker MD. Available from: URL: http://www.orthoassociates.com

9. Price DD, McGrath PA, Rafii A, Buckingham B. The validation of visual analogue scales as ratio scale measures for chronic pain and experimental pain. Pain 1983;17:45-56. [CrossRef]

10. Insall JN, Dorr LD, Scott RD, Scott WN. Rationale of the Knee Society clinical rating system. Clin Orthop Relat Res 1989;248:13-4. [CrossRef]

11. Demirsoy AC. The MOS SF-36 Health Survey: A validation study with a Turkish sample (Thesis). Bogazici University. Istanbul, 1999. Available from: http://seyhan.library.boun.edu.tr/search/a?SEA $\mathrm{RCH}=\mathrm{DEM} \% \mathrm{C} 4 \% \mathrm{BORSOY}+$ Ahmet+Cengizhan\&sortdropdown=\&searchscope $=5$.

12. Mahomed NN, Koo Seen Lin MJ, Levesque J, Lan S, Bogoch ER. Determinants and outcomes of inpatient versus home based rehabilitation following elective hip and knee replacement. J Rheumatol 2000;27:1753-8. [CrossRef]

13. Barrois B, Gouin F, Ribinik P, Revel M, Rannou F. What is the interest of rehabilitation in physical medicine and functional rehabilitation ward after total hip arthroplasty? Elaboration of French clinical practice guidelines. Ann Readapt Med Phys 2007;50:700-4. [CrossRef]

14. Mahomed NN, Davis AM, Hawker G, Badley E, Davey JR, Syed $K A$, et al. Inpatient compared with home-based rehabilitation following primary unilateral total hip or knee replacement: A randomized controlled trial. J Bone Joint Surg Am 2008; 90:1673-80. [CrossRef]

15. Stevens JE, Mizner RL, Snyder-Mackler L. Neuromuscular electrical stimulation for quadriceps muscle strengthening after bilateral total knee arthroplasty: a case series. J Orthop Sports Phys Ther 2004;34:21-9. [CrossRef] 
16. Moffet H, Collet JP, Shapiro SH, Paradis G, Marquis F, Roy L. Effectiveness of intensive rehabilitation on functional ability and quality of life after first total knee arthroplasty: a single-blind randomized controlled trial. Arch Phys Med Rehabil 2004;85:546-56. [CrossRef]

17. Munin MC, Rudy TE, Glynn NW, Crosset LS, Rubash HE. Early inpatient rehabilitation after elective hip and knee arthroplasty. JAMA 1998;279:847-52. [CrossRef]

18. Forrest GP, Roque JM, Dawodu ST. Decreasing length of stay after total joint arthroplasty: effect on referrals to rehabilitation units. Arch Phys Med Rehabil 1999;80:192-4. [CrossRef]
19. Oldmeadow LB, McBurney $H$, Robertson VJ. Predicting risk of extended inpatient rehabilitation after hip or knee arthroplasty. J Arthroplasty 2003;18:775-9. [CrossRef]

20. Noble PC, Scuderi GR, Brekke AC, Sikorskii A, Benjamin JB, Lonner $\mathrm{JH}$, et al. Development of a new Knee Society scoring system. Clin Orthop Relat Res 2012;470:20-32. [CrossRef]

21. Scuderi GR, Bourne RB, Noble PC, Benjamin JB, Lonner JH, Scott WN. The new Knee Society Knee Scoring System. Clin Orthop Relat Res 2012;470:3-19. [CrossRef] 